\title{
Sleep and breathing in neuromuscular disease
}

\author{
S.C. Bourke, G.J. Gibson
}

\begin{abstract}
Sleep and breathing in neuromuscular disease. S.C. Bourke, G.J. Gibson. (C)ERS Journals Ltd 2002.

ABSTRACT: Respiratory muscle weakness in neuromuscular disease causes significant morbidity and mortality. The published data on respiratory muscle activity and breathing during sleep in normal subjects, the impact of respiratory muscle weakness on sleep and breathing and the relations to daytime respiratory function in neuromuscular disease are reviewed here. In normal subjects during sleep upper airway resistance increases, chemosensitivity is reduced and the wakefulness drive to breathe is lost, resulting in a fall in ventilation. During rapid eye movement (REM) sleep, ribcage and accessory breathing muscles are suppressed, particularly during bursts of eye movements, and breathing is more irregular, rapid and shallow, with a further fall in ventilation.

In subjects with respiratory muscle weakness sleep is fragmented, with shorter total sleep time, frequent arousals, an increase in stage 1 sleep and a reduction in, or complete suppression of, REM sleep. Sleep-disordered breathing and nocturnal desaturation are common and most severe during REM sleep. Correlations between daytime respiratory function and nocturnal desaturation are moderate or weak, but daytime respiratory function has greater prognostic value than nocturnal measurements.

Noninvasive ventilation improves sleep quality and breathing in subjects with respiratory muscle weakness. However, the optimal criteria for initiation of ventilation and its role in rapidly progressive neuromuscular diseases are unclear.
\end{abstract}

Eur Respir J 2002; 19: 1194-1201.

University of Newcastle and Freeman Hospital, Newcastle upon Tyne, UK.

Correspondence: S.C. Bourke Sir William Leech Centre for Lung Research,

Freeman Hospital,

Newcastle upon Tyne,

NE7 7DN,

UK.

Fax: 441912132690

E-mail: sbourke@doctors.org.uk

Keywords: Neuromuscular diseases polysomnography

respiratory muscles

sleep

Received: August 102001

Accepted after revision January 82002
Respiratory muscle weakness and sleep-disordered breathing are both common in neuromuscular diseases such as amyotrophic lateral sclerosis (ALS) [1-5], muscular dystrophies (e.g. Duchenne's muscular dystrophy (DMD) [6-10], and myotonic dystrophy (MD) [11-14], myopathies (e.g. nemaline myopathy [15]), Guillian-Barré syndrome and myasthenia gravis [16-18]. Respiratory muscle weakness, apnoeas and hypopnoeas, and abnormalities of breathing pattern and ventilatory drive may all contribute to nocturnal desaturation and sleep disruption, even before daytime ventilatory failure ensues. Patients with severe respiratory muscle weakness frequently complain of unrefreshing sleep, daytime sleepiness, impaired concentration, fatigue and lethargy due to nocturnal hypoventilation and sleep disruption $[2-4,7,11,19$, $20]$. The risk of respiratory infections is increased by impairment of cough due to respiratory muscle or bulbar weakness, and death is frequently due to respiratory failure.

There is increasing evidence that noninvasive ventilation (NIV) improves survival [21-24] and quality of life [25] in neuromuscular disease complicated by respiratory muscle weakness. The prevalence of respiratory muscle weakness and sleep disruption in neuromuscular disease, the associated morbidity and mortality, and the potential efficacy of NIV emphasize the importance of understanding the adverse effects of weakness on sleep and nocturnal oxygenation, and of recognizing the resulting symptoms at an early stage. The role of overnight monitoring by either detailed polysomnography (PSG) or simple oximetry in clinical assessment of these patients is uncertain. In this review the normal effects of sleep on muscle activity and breathing are described, and then the evidence on disruption of sleep architecture, sleep-disordered breathing and nocturnal oxygenation in neuromuscular disease is reviewed. In particular, the relations between symptoms, daytime respiratory function and sleep-disordered breathing and sleep disruption are explored. Finally, the more specific findings in various diseases, and the impact of NIV on sleep and breathing in neuromuscular disease are described.

\section{Normal breathing and muscle activity during sleep}

Indices of ventilation during wakefulness and sleep are shown in figure 1 [26].

\section{Nonrapid eye movement sleep}

Electromyogram (EMG) studies have shown that at sleep onset (transition from alpha to theta electroencephalogram (EEG) activity) phasic diaphragmatic, intercostal and genioglossus activity fall and then rise again, while phasic and tonic activity of tensor palatini falls abruptly and remains low [27]. 
a)

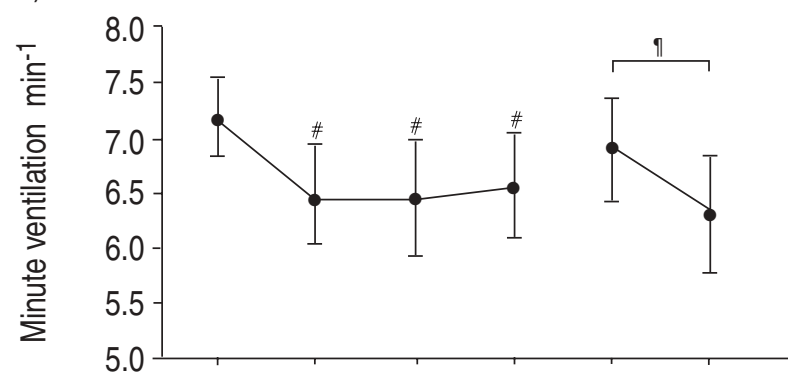

b)

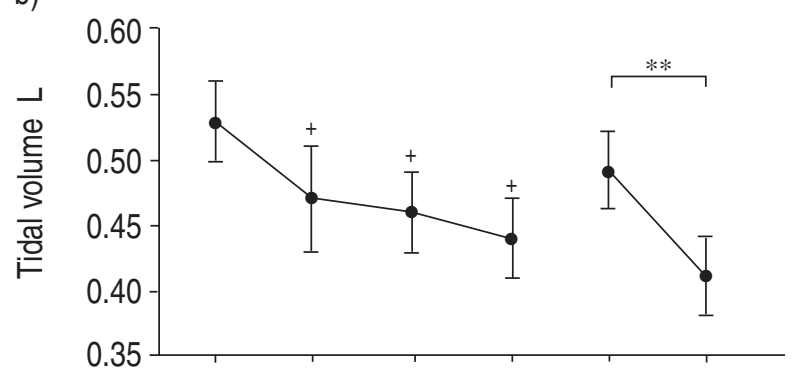

c)

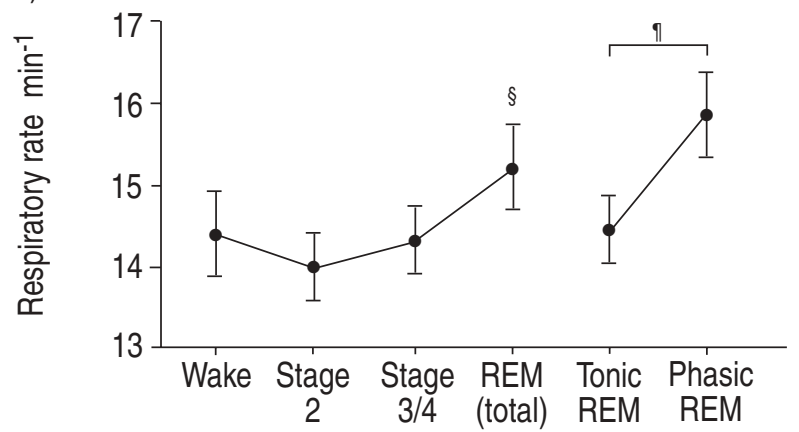

Fig. 1.-a) Minute ventilation, b) tidal volume and c) respiratory rate during wakefulness and sleep in 10 normal adult subjects. Data are presented as mean \pm SEM. \#. Ventilation lower during sleep compared to wake $\mathrm{p}<0.02 ;{ }^{\uparrow}: \mathrm{p}=0.01 ;{ }^{+}$: tidal volume lower during sleep compared to wake $\mathrm{p}<0.05 ; * *$ : $\mathrm{p}<0.01$; ${ }^{\S}$ : respiratory rate higher in rapid eye movement (REM) compared to nonrapid eye movement sleep (NREM) or wake $\mathrm{p}<0.05$. Data from GOULD et al. [26].

Ventilation falls abruptly and is associated with a more rapid, shallow and regular breathing pattern [28], resulting in a rise in the partial pressure of carbon dioxide $\left(\mathrm{PCO}_{2}\right)[28,29]$. Ventilation shows only a slight further decline once sleep becomes established. Upper airway resistance (UAR) increases abruptly at sleep onset due to reduced activity of the pharyngeal dilator muscles but, in contrast to ventilation, there is a further progressive rise in UAR associated with increasing delta EEG activity in slow-wave sleep [30]. The increase in phasic diaphragmatic and intercostal EMG activity in nonrapid eye movement (NREM) sleep (following the transient fall at sleep onset) reflects the rise in respiratory workload due to increased UAR. In subjects with a tracheostomy, the fall in ventilation and rise in end-tidal $\mathrm{PCO}_{2}$ during sleep are similar to normal subjects [31]. This supports the hypothesis that the changes in ventilation during sleep result primarily from a reduction in ventilatory drive due to reduced chemosensitivity [29, 32] and loss of the wakefulness drive to breathe [33], rather than from the increase in UAR. The rise in genioglossus activity during NREM sleep, after the initial fall at sleep onset, may be important in maintaining airway patency [34].

\section{Rapid eye movement sleep}

During rapid eye movement (REM) sleep there is a marked generalized reduction in the tone of skeletal muscles, with the exception of the diaphragm and extra-ocular muscles [35]. Douglas et al. [28] reported a further fall in tidal volume (due to reduced ribcage contribution), minute ventilation and mean inspiratory flow (an index of ventilatory drive) from NREM to REM sleep. Two smaller studies reported only a trend for a fall in tidal volume, with no significant reduction in ventilation during REM compared to NREM. Although the ribcage contribution decreased, its effect was balanced by increased diaphragmatic activity [36] and respiratory rate [26].

REM sleep is not a homogeneous state, but comprises phasic REM associated with bursts of rapid eye movements, and tonic REM, between bursts of rapid eye movements. In comparison to tonic REM, phasic REM is associated with smaller tidal volume (due to less ribcage contribution), higher respiratory rate (due to a fall in expiratory time) [26, $36,37]$ and lower minute ventilation. The breathing pattern is also more irregular [26, 36]. The changes in tidal volume and respiratory rate are proportional to the intensity of the rapid eye movements $[26,36]$. Increasing phase shift between ribcage and abdominal movements accompanying the rapid eye movements has also been described, and may reflect relatively greater inhibition of the upper airway musculature leading to pharyngeal narrowing during eye movements [36].

In summary, REM sleep in healthy subjects is associated with a shift from predominantly ribcage to diaphragmatic breathing, and is heterogeneous; during bursts of rapid eye movements breathing is more irregular, rapid and shallow, with an overall fall in ventilation.

\section{Neuromuscular disease}

Muscle activity: adaptive mechanisms in respiratory muscle weakness

In some patients with respiratory muscle weakness, expiratory contraction of the abdominal muscles has been shown during wakefulness and NREM sleep (semirecumbent). Subsequent relaxation of the abdominal muscles at the onset of inspiration aids diaphragmatic descent and inspiration [38, 39].

Subjects with diaphragmatic weakness are particularly vulnerable to REM-related hypoventilation and desaturation. Unusual phasic inspiratory activity of sternocleidomastoid during REM has been reported in a proportion of subjects with severe diaphragmatic 
weakness due to ALS, which may be another acquired adaptive mechanism [1].

\section{Sleep architecture}

Reduced total sleep time [2,3] and sleep efficiency [2] are well described in patients with respiratory muscle weakness. Marked sleep fragmentation is commonly seen in subjects with respiratory or sleeprelated symptoms $[3,38]$ with frequent arousals $[2,3$, $10]$, an increase in stage 1 sleep $[3,7]$ and reduction in REM sleep [1, 7, 38]. Complete suppression of REM has been reported in association with severe diaphragmatic weakness [1,38]. As these subjects are most vulnerable to oxygen desaturation during REM sleep, its suppression may represent a compensatory mechanism. Studies in subjects with equivalent respiratory function have shown substantial variation in the degree of sleep disruption, which at least in part, appears to be related to the reported prevalence of symptoms $[2,3,7-9,40]$. In other populations sleeprelated symptoms have a large impact on quality of life, shown, for example, by short form 36 (SF-36) health status scores in untreated obstructive sleep apnoea, and the improved scores on continuous positive airway pressure therapy. The quality of life of patients with ALS correlates with both daytime respiratory muscle function and polysomnographic indices [41].

\section{Sleep breathing disorders in neuromuscular disease}

The commonest form of sleep-disordered breathing in patients with respiratory muscle weakness is hypoventilation due to reduced tidal volume, particularly during REM sleep [3, 4]. Similar REM-related hypoventilation has been described in several other situations (e.g. chronic obstructive pulmonary disease (COPD), cystic fibrosis and obesity hypoventilation syndrome) [42]. The degree of overall hypoventilation is not consistently reported, perhaps reflecting the difficulty of quantitating hypoventilation compared to apnoeas and hypopnoeas. The distinction between hypoventilation and central hypopnoeas is arbitrary; the latter usually refer to discrete short periods when ventilation is reduced compared to a preceding reference period.

A high prevalence of sleep-disordered breathing has been reported in neuromuscular disease, irrespective of the primary disorder $[2,3,7-10,13,40]$. The definition of apnoea is consistent in the vast majority of studies, but definitions of hypopnoea differ, depending whether oxygen desaturation (3 or $4 \%$ ) and/or EEG arousal must also be present. The classification of events as "central" or "obstructive" using noninvasive monitoring is particularly difficult in neuromuscular disease. Obstructive apnoea may be misclassified as central when respiratory muscles are too weak to move the chest wall against a closed pharynx. SмIтн et al. [9] showed phasic submental EMG activity during apparent central apnoeas in two subjects with DMD, and coined the term "pseudocentral apnoea". There are even greater pitfalls in the classification of hypopnoeas. Severe diaphragmatic weakness causes paradoxical movement of the chest and abdomen even without narrowing of the upper airway, which may cause misclassification of central hypopnoeas as obstructive. An increasing phase difference between chest and abdominal movements, stable or increasing submental EMG (particularly at the end of the event), phasic diaphragmatic EMG activity, and snoring provide strong supportive evidence for an obstructive aetiology [38].

The most frequently reported discrete sleep-breathing events in patients with respiratory muscle weakness are central hypopnoeas $[3,7,9,13,16,40]$, which are more frequent and prolonged in REM sleep [3, 7, 9, 13, 16], particularly phasic REM [38]. During REM sleep, suppression of the intercostal and accessory respiratory muscles (including the abdominal muscles), combined with inadequate diaphragmatic recruitment, leads to hypoventilation. The degree of muscle suppression, and consequent reduction in ventilation, is proportional to the density of eye movements, and often meets the criteria for central hypopnoea during bursts of rapid eye movements. The degree of desaturation is related to the severity of diaphragmatic weakness [38, 39].

In some studies predominantly obstructive events have been reported, either in a substantial proportion of subjects $[7,10,38]$ or overall $[4,8,40]$. Obstructive events are more likely in subjects with a high body mass index (BMI) [40], who snore [7, 40], or have anatomical abnormalities such as macroglossia (e.g. in DMD) [7]. Increased UAR during REM sleep may also contribute to obstructive apnoeas or hypopnoeas [8]. Discrepancies in the proportion of obstructive events between studies of subjects with the same underlying condition and similar respiratory function are considerable. For example, Ferguson et al. [3] reported purely central events in 17 subjects with bulbar ALS and mean vital capacity (VC) of $81 \%$, while GAY et al. [4] reported predominantly obstructive events in 16 of 18 subjects with ALS and a mean $\mathrm{VC}$ of $82 \%$. A similar discrepancy is seen in other neuromuscular diseases, such as DMD [7, 8] and MD $[13,14]$, and may reflect the inherent difficulty in classifying events using noninvasive monitoring. Notably, studies in which oesophageal pressure was recorded to accurately determine the nature of events have reported predominantly central events $[13,16]$.

The apnoea/hypopnoea index (AHI) has been shown to correlate to varying degrees with excessive daytime somnolence [2, 4], daytime arterial oxygen tension [7] and total lung capacity (TLC) [10] although not consistently. Overall however, the relation between the AHI and either sleep-related symptoms $[13,40]$ or respiratory muscle function $[7$, $10,11,13,40]$ is poor.

Nocturnal oxygenation in neuromuscular disease, relation to daytime lung function and symptoms

In subjects with respiratory muscle weakness, nocturnal desaturation may occur due to any or all of the following: 1) overall hypoventilation, 2) periodic apnoeas and hypopnoeas, and probably 3 ) ventilation/perfusion mismatching due to increased 


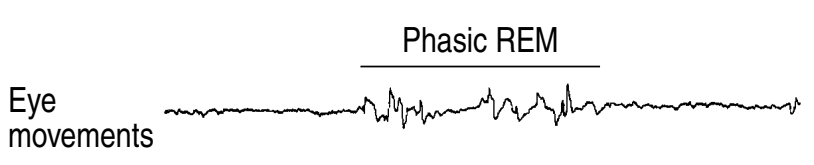

Airflow murnommormm

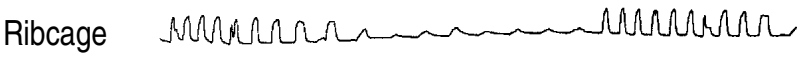

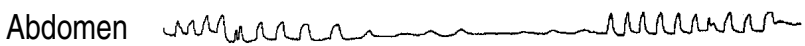

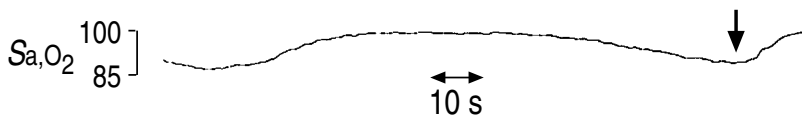

Fig. 2.-Suppression of airflow, chest and abdominal movement during tonic and phasic rapid eye movement (REM). Phasic REM is identified by the burst of rapid eye movements, and indicated by a bar. The consequent reduction in the arterial oxygen saturation $\left(\mathrm{Sa}_{\mathrm{a}} \mathrm{O}_{2}\right)$ is indicated by the arrow.

atelectasis in the supine posture. The most profound desaturation occurs during REM [3, 8, 9, 39, 42], particularly phasic REM [38], usually related to central hypopnoeas/hypoventilation $[3,7,9,10,13$, 38, 40] (fig. 2). In patients with neuromuscular disease nocturnal oxygenation tends to be lower with increasing age and BMI [9, 39, 40].

Several studies have examined the relationship between daytime respiratory function and nocturnal oxygenation. As would be expected, indices of nocturnal saturation correlate with daytime arterial blood gases [7, 10, 39] and saturation [40]. However, since nocturnal desaturation is likely to precede daytime respiratory failure more sensitive predictors of nocturnal desaturation have been sought. Less consistent and weaker relationships have been shown between nocturnal oxygen saturation and VC [10, 39, 40], fall in VC supine [38, 39], forced expiratory volume in one second (FEV1) [10], maximal expiratory pressure (PE,max) [9] and functional residual capacity [43] (table 1). However, it is important to note that indices of daytime lung function ( $\mathrm{VC}$ and maximal inspiratory pressure $(P \mathrm{I}, \max ))$ are better predictors of survival than overnight oxygen saturation $[4,44]$ and orthopnoea in the presence of substantial impairment of daytime respiratory muscle function may be a better predictor of benefit from NIV than nocturnal desaturation [45].

Sleep-disordered breathing and nocturnal oxygen desaturation may be predicted by orthopnoea [2], waking with a sensation of breathlessness [16], excessive daytime somnolence $[2,4,16]$ and difficulty sleeping [4]. GAY et al. [4] found that excessive daytime somnolence was $100 \%$ sensitive (although only $57 \%$ specific) for predicting nocturnal desaturation. There is conflicting evidence on the relationship between symptoms and sleep-disordered breathing and nocturnal desaturation in subjects with DMD and equivalent daytime respiratory function [7,9]. Sleep symptoms may be under-reported by patients and, in very disabling conditions, are easily overlooked by clinicians [7]. This emphasizes the importance of careful clinical evaluation for orthopnoea and sleeprelated symptoms, which in the presence of moderate or severe respiratory muscle weakness may be an effective means of selecting patients for NIV.

\section{Features specific to individual disorders}

\section{Isolated diaphragmatic paralysis}

Subjects with isolated diaphragmatic paralysis are particularly prone to nocturnal desaturation during REM sleep [38], even with only unilateral involvement [46]. Although few detailed polysomnographic studies have been performed in such patients, REM sleep [46] and slow-wave sleep (SWS) are likely to be reduced $[38,46]$. Daytime respiratory failure is unusual with

Table 1. - Relations between daytime pulmonary function tests and nocturnal oxygen saturation $\left(\mathrm{Sa}_{2}, \mathrm{O}_{2}\right)$ in neuromuscular disease

\begin{tabular}{|c|c|c|c|c|c|c|c|c|}
\hline \multirow[t]{2}{*}{ First author [ref. no.] } & \multirow[t]{2}{*}{ Disorder } & \multirow[t]{2}{*}{ Subjects $n$} & \multicolumn{6}{|c|}{ Daytime function correlation with nocturnal $S_{\mathrm{a}, \mathrm{O}_{2}}(\mathrm{r})$} \\
\hline & & & $\mathrm{Pa}, \mathrm{CO}_{2}$ & $\mathrm{VC}$ & $\Delta \mathrm{VC}$ & $P \mathrm{I}, \max$ & $P$ E,max & Lung volumes \\
\hline DAVID [2] & ALS & 17 & & NS & & $\mathrm{NS}$ & & \\
\hline GAY [4] & ALS & 21 & -0.66 & $\mathrm{NS}^{\circ}$ & & $\mathrm{NS}^{\bullet}$ & $\mathrm{NS}^{\bullet}$ & \\
\hline SMITH [9] & DMD & 14 & NS & NS & NS & NS & $\mathrm{p}<0.05^{+}$ & NS \\
\hline HUKINS [10] & DMD & 19 & 0.71 & -0.46 & & NS & NS & NS \\
\hline MANNI [39] & DMD & 11 & NS & NS & NS & NS & NS & $\begin{array}{c}\text { FRC } 0.68 \\
\text { RV } 0.67\end{array}$ \\
\hline FINNIMORE [11] & MD & 12 & NS & NS & NS & NS & NS & NS \\
\hline WHITE [33] & Various & 8 & & NS & -0.78 & NS & NS & NS \\
\hline LABANOSWKI [34] & Various & 60 & $\mathrm{NS}^{\#}$ & 0.35 & NS & NS & NS & \\
\hline BYE [37] & Various & 20 & 0.59 & 0.79 & 0.59 & NS & NS & NS \\
\hline
\end{tabular}

ALS: amyotrophic lateral sclerosis; DMD: Duchenne muscular dystrophy; MD: myotonic dystrophy; $\Delta$ VC: $\%$ fall in vital capacity on lying supine; $P \mathrm{a}, \mathrm{CO}_{2}$ : carbon dioxide tension in arterial blood; $P$ I,max: maximal inspiratory pressure; $P$ E,max: maximal expiratory pressure; NS: nonsignificant. Studies used different indices of nocturnal desaturation, which influenced the direction of the correlation (e.g. mean $\mathrm{Sa}_{\mathrm{a}} \mathrm{O}_{2}$ versus time $\mathrm{S}_{\mathrm{a}, \mathrm{O}_{2}}<90 \%$ ). No study applied a correction for multiple comparisons. Values with $\mathrm{p}<0.05$ are shown. ${ }^{\#}$ : Correlation with awake $S \mathrm{a}, \mathrm{O}_{2}=0.78$; ": poor or nonsignificant; ${ }^{+}$: desaturators versus nondesaturators, t-test. 
isolated bilateral diaphragmatic paralysis unless there is coexisting intrinsic lung disease (e.g. COPD) or obesity [38, 46-49].

\section{Amyotrophic lateral sclerosis}

Most studies in ALS have been conducted on selected populations, e.g. with bulbar involvement [3], diaphragmatic involvement [1] or in the presence [2] or absence [50] of respiratory and/or sleep-related symptoms. In the largest unselected cross-sectional study, GAY et al. [4] reported a mean AHI of 11.3 events $\cdot h^{-1}$ in 21 subjects, of whom seven had an AHI $>10$. However, the principal cause of nocturnal desaturation was hypoventilation. Comparing the PSG results of the various studies, the frequency of sleepdisordered breathing is very variable $(16.7-76.5 \%)$, and appears to reflect the prevalence of respiratory and sleep-related symptoms, and to a lesser extent, the impairment of daytime respiratory function in the populations studied $[2-5,50]$. A similar variation is seen with the degree of disruption of sleep architecture [1,3-5]. Diaphragmatic paresis or paralysis is associated with sleep disruption and a reduction in, or complete suppression of, REM [1]. No significant relations between bulbar involvement and the severity of sleep-disordered breathing or the type of event (obstructive or central) have been reported $[1-5,50]$. Nocturnal desaturation and sleep disruption in ALS therefore appear to be due mainly to diaphragmatic weakness and hypoventilation, rather than to obstructive events due to bulbar weakness [1].

\section{Duchenne muscular dystrophy}

One study in 21 subjects with DMD using automated analysis reported apnoeas, which initially were mainly obstructive, but with disease progression the proportion of central apnoeas increased. The authors concluded that sleep-disordered breathing in DMD was initially obstructive in nature (which might have therapeutic implications), and suggested that the apparent increase in central events in serial studies may be due to misclassification ("pseudo-central" events) [8]. Snoring and macroglossia are associated with obstructive apnoeas and hypopnoeas in DMD [7], but most studies have reported predominantly central events $[7,9,10,43]$. These data are supported by studies in other conditions in which oesophageal pressure was monitored to accurately stage events $[13,16]$.

In comparison to subjects with ALS and a similar impairment of daytime respiratory function, sleep architecture appears to be better preserved in DMD. In common with other neuromuscular conditions, the relation between daytime function and nocturnal oxygen desaturation or respiratory events is poor $[7,9$, 10], but daytime function, specifically $\mathrm{VC}<1 \mathrm{~L}$, is a more powerful prognostic predictor than any nocturnal index [44]. Evidence on the relationships between sleep-disordered breathing and symptoms is contradictory [7-9], which may reflect how carefully symptoms were sought.

\section{Myotonic dystrophy}

Daytime somnolence, hypercapnia, sleep-disordered breathing and nocturnal desaturation are all common in MD [11-13]. Furthermore, the AHI and degree of nocturnal desaturation are greater than in nonmyotonic neuromuscular disease with a similar degree of respiratory muscle weakness [12]. Subjects with MD tend to be heavier than those with other forms of neuromuscular disease [12], and the degree of nocturnal desaturation is related to the BMI [11]. In most patients with MD sleepiness is not clearly attributable to hypercapnia, sleep-disordered breathing or disturbance of sleep architecture [12,51]. MD is also associated with an irregular breathing pattern during wakefulness [52] and light sleep, which does not persist during SWS [51, 53], suggesting that the defect may be due to cortical, rather than medullary/ central (chemosensitive drive) influences. Such irregularity of breathing pattern is not seen in nonmyotonic subjects with similar respiratory muscle weakness [53].

\section{Myasthenia gravis}

Several investigators have suggested that sleeprelated symptoms in myasthesia gravis (MG) might reflect central nervous system involvement or occur as a side-effect of anticholinesterase therapy, yet there is little evidence to support this [54]. Sleep-disordered breathing is common in MG associated with peripheral respiratory muscle weakness, particularly diaphragmatic weakness. In common with other conditions, sleep-disordered breathing and nocturnal desaturation are most pronounced during REM sleep $[16,18]$ and the majority of respiratory events are central. Older patients with a higher BMI, lower TLC and abnormal daytime arterial blood gases are most vulnerable [16]. Sleep-disordered breathing and nocturnal desaturation may improve following treatment with thymectomy [17] or prednisolone [18].

\section{Impact of noninvasive ventilation on sleep in respiratory muscle weakness}

\section{Negative-pressure ventilation}

Negative-pressure ventilation was introduced in the 1950 s to treat victims of the polio epidemics with respiratory failure. It has been shown to improve oxygenation, particularly during NREM sleep. Sleep architecture remains fragmented with frequent arousals [55]. Episodes of severe desaturation still occur, particularly during REM sleep, associated with obstructive events. Negative-pressure ventilation contributes to upper airway obstruction both in subjects with neuromuscular disease [55-57] and in normal individuals [58]. Both continuous positive airway pressure and tracheostomy reduce sleep-disordered 
breathing and improve sleep architecture in subjects receiving negative-pressure ventilation [56]. While negative-pressure ventilation resembles the normal physiological thoracic and diaphragmatic inspiratory process more closely than positive-pressure ventilation, phasic inspiratory activity in the pharyngeal muscles supporting the upper airway is not stimulated, leading to frequent obstructive events and arousals.

\section{Positive-pressure ventilation}

In uncontrolled studies, positive-pressure ventilation improves nocturnal saturation, sleep-disordered breathing, sleep efficiency, and sleep architecture in neuromuscular disease [59, 60]. The upper airway is supported, preventing obstructive apnoeas or hypopnoeas, and leading to a greater improvement in both oxygenation $[55,57]$ and sleep architecture than seen with negative-pressure ventilation [55]. Daytime arterial blood gases improve with long-term nocturnal ventilation [59-62], and are associated with an increased ventilatory response to carbon dioxide [60].

No randomized-controlled trials of NIV initiated for hypercapnic respiratory failure have been performed in stable or slowly progressive neuromuscular disease, however NIV appears to improve survival compared to historical controls [21]. In DMD specifically, NIV is associated with longer survival in subjects with symptomatic daytime hypercapnia when compared to those who declined NIV [63] or historical controls [22]. Surprisingly, one randomized-controlled trial comparing earlier intervention (VC 20-50\% predicted, normal daytime $\mathrm{PCO}_{2}$ ) with no NIV was associated with higher mortality in the treated group. The excess mortality was due to deaths from respiratory infections and retention of secretions. Although there was no difference in the frequency of respiratory infections in the two groups, fewer patients in the NIV group were treated with invasive ventilation ( 9 versus $26 \%$ ), and most deaths occurred in subjects managed at home. The authors concluded that NIV did not increase the risk of respiratory infections, but false security may subsequently have led to suboptimal medical management [64]. In contrast, successful treatment with NIV has been described in symptomatic patients with normal daytime carbon dioxide tension in arterial blood suffering from various neuromuscular conditions including muscular dystrophy [65].

In more rapidly progressive conditions such as ALS, NIV also appears to prolong survival [23, 24] and improve quality of life [25] although, at present, no randomized-controlled trials have been reported and the optimal timing of intervention is unclear. Although randomized-controlled trials data are lacking, in light of evidence of improvements in symptoms, daytime hypercapnia, nocturnal desaturation and 1-yr mortality, NIV is recommended in neuromuscular disease [66]. Recent consensus guidelines suggest that it should be initiated for symptoms with either daytime hypercapnia or nocturnal desaturation (arterial oxygen saturation $\leqslant 88 \%$ for $5 \mathrm{~min}$ ).
In progressive neuromuscular disease NIV is also recommended if symptoms are present with $P$ I,max $<60 \mathrm{cmH}_{2} \mathrm{O}$ or $\mathrm{VC}<50 \%$ pred [67]. In the authors experience the emphasis on symptoms is particularly important and, at least in ALS, earlier intervention in the presence of orthopnoea with sleep-related symptoms and $P \mathrm{I}$,max $<60 \%$ pred even before development of daytime hypercapnia is associated with improved symptoms and quality of life [45].

\section{Conclusions and practical considerations}

Sleep-disordered breathing, sleep disruption and nocturnal desaturation are common in neuromuscular disease associated with respiratory muscle weakness. With severe weakness, diurnal respiratory failure often ensues. Symptoms related to sleep disruption and hypercapnia are a major cause of morbidity. Noninvasive positive-pressure ventilation improves sleep-disordered breathing, sleep architecture and more importantly, symptoms, quality of life and survival in slowly or nonprogressive neuromuscular disease, and probably also in more rapidly progressive diseases, such as ALS. The optimal time to initiate treatment and the roles of polysomnography or nocturnal oximetry in assessing patients have yet to be clearly defined.

Screening sleep studies have been recommended in patients with neuromuscular disease, often guided by serial daytime respiratory function tests (typically spirometry plus/minus blood gases) [9, 10, 39, 40]. However in comparison to daytime lung function, nocturnal measurements, including oxygen saturation, are surprisingly weak predictors of survival [4, 44]. In amyotrophic lateral sclerosis orthopnoea (due to respiratory muscle weakness) is a more sensitive predictor of benefit from noninvasive ventilation than either nocturnal desaturation or daytime hypercapnia and the apnoea/hypopnoea index is unhelpful [45]. The studies available cast doubt on the need for routine polysomnography or nocturnal oximetry in assessing such patients for noninvasive ventilation, although polysomnography may identify the occasional patient with coexistent obstructive sleep apnoea. There is a need for further studies evaluating the optimal criteria for and timing of initiating noninvasive ventilation in patients with neuromuscular disease. Currently there is no evidence that sleep studies improve the selection of subjects for noninvasive ventilation over and above evaluation of symptoms and daytime respiratory function.

\section{References}

1. Arnulf I, Similowski T, Salachas F, et al. Sleep disorders and diaphragmatic function in patients with amyotrophic lateral sclerosis. Am J Respir Crit Care Med 2000; 161: 849-856.

2. David WS, Bundlie SR, Mahdavi Z. Polysomnographic studies in amyotrophic lateral sclerosis. J Neurol Sci 1997; 152: Suppl. 1, S29-S35.

3. Ferguson KA, Strong MJ, Ahmad D, George CF. 
Sleep-disordered breathing in amyotrophic lateral sclerosis. Chest 1996; 110: 664-669.

4. Gay PC, Westbrook PR, Daube JR, Litchy WJ, Windebank AJ, Iverson R. Effects of alterations in pulmonary function and sleep variables on survival in patients with amyotrophic lateral sclerosis. Mayo Clin Proc 1991; 66: 686-694.

5. Minz M, Autret A, Laffont F, Beillevaire T, Cathala HP, Castaigne P. A study on sleep in amyotrophic lateral sclerosis. Biomedicine 1979; 30: 40-46.

6. Kirk VG, Flemons WW, Adams C, Rimmer KP, Montgomery MD. Sleep-disordered breathing in Duchenne muscular dystrophy: a preliminary study of the role of portable monitoring. Pediatr Pulmonol 2000; 29: 135-140.

7. Barbe F, Quera-Salva MA, McCann C, et al. Sleeprelated respiratory disturbances in patients with Duchenne muscular dystrophy. Eur Respir J 1994; 7: 1403-1408.

8. Khan Y, Heckmatt JZ. Obstructive apnoeas in Duchenne muscular dystrophy. Thorax 1994; 49: 157-161.

9. Smith PE, Calverley PM, Edwards RH. Hypoxemia during sleep in Duchenne muscular dystrophy. Am Rev Respir Dis 1988; 137: 884-888.

10. Hukins CA, Hillman DR. Daytime predictors of sleep hypoventilation in Duchenne muscular dystrophy. Am J Respir Crit Care Med 2000; 161: 166-170.

11. Finnimore AJ, Jackson RV, Morton A, Lynch E. Sleep hypoxia in myotonic dystrophy and its correlation with awake respiratory function. Thorax 1994; 49: 66-70.

12. Gilmartin JJ, Cooper BG, Griffiths CJ, et al. Breathing during sleep in patients with myotonic dystrophy and non-myotonic respiratory muscle weakness. QJM 1991; 78: 21-31.

13. Cirignotta F, Mondini S, Zucconi M, et al. Sleeprelated breathing impairment in myotonic dystrophy. J Neuroly 1987; 235: 80-85.

14. Guilleminault C, Cummiskey J, Motta J, LynneDavies P. Respiratory and hemodynamic study during wakefulness and sleep in myotonic dystrophy. Sleep 1978; 1: 19-31.

15. Sasaki M, Takeda M, Kobayashi K, Nonaka I. Respiratory failure in nemaline myopathy. Pediatr Neurol 1997; 16: 344-346.

16. Quera-Salva MA, Guilleminault C, Chevret S, et al. Breathing disorders during sleep in myasthenia gravis. Ann Neurol 1992; 31: 86-92.

17. Amino A, Shiozawa Z, Nagasaka $T$, et al. Sleep apnoea in well-controlled myasthenia gravis and the effect of thymectomy. $J$ Neurol 1998; 245: 77-80.

18. Papazian O. Rapid eye movement sleep alterations in myasthenia gravis. Neurology 1976; 26: 311-316.

19. Howard RS, Wiles CM, Loh L. Respiratory complications and their management in motor neuron disease. Brain 1989; 112: 1155-1170.

20. Howard RS, Wiles CM, Hirsch NP, Spencer GT. Respiratory involvement in primary muscle disorders: assessment and management. QJM 1993; 86: 175-189.

21. Simonds AK, Elliott MW. Outcome of domiciliary nasal intermittent positive pressure ventilation in restrictive and obstructive disorders. Thorax 1995; 50: 604-609.

22. Simonds AK, Muntoni F, Heather S, Fielding S. Impact of nasal ventilation on survival in hypercapnic
Duchenne muscular dystrophy. Thorax 1998; 53: 949-952.

23. Pinto AC, Evangelista T, Carvalho M, Alves MA, Sales Luis ML. Respiratory assistance with a noninvasive ventilator (Bipap) in MND/ALS patients: Survival rates in a controlled trial. J Neurol Sci 1995; 129: Suppl., 19-26.

24. Kleopa KA, Sherman M, Neal B, Romano GJ, Heiman-Patterson T. Bipap improves survival and rate of pulmonary function decline in patients with ALS. J Neurol Sci 1999; 164: 82-88.

25. Lyall RA, Donaldson $\mathrm{N}$, Fleming $\mathrm{T}$, et al. A prospective study of quality of life in ALS patients treated with noninvasive ventilation. Neurology 2001; 57: $153-156$

26. Gould GA, Gugger M, Molloy J, Tsara VMSC, Douglas NJ. Breathing pattern and eye movement density during REM sleep in humans. Am Rev Respir Dis 1988; 138: 874-877.

27. Worsnop C, Kay A, Pierce R, Kim Y, Trinder J. Activity of respiratory pump and upper airway muscles during sleep onset. J Appl Physiol 1998; 85: 908-920.

28. Douglas NJ, White DP, Pickett CK, Weil JV, Zwillich CW. Respiration during sleep in normal man. Thorax 1982; 37: 840-844.

29. Simon PM, Dempsey JA, Landry DM, Skatrud JB. Effect of sleep on respiratory muscle activity during mechanical ventilation. Am Rev Respir Dis 1993; 147: 32-37.

30. Kay A, Trinder J, Kim Y. Progressive changes in airway resistance during sleep. J Appl Physiol 1996; 81: 282-296.

31. Morrell MJ, Harty HR, Adams L, Guz A. Breathing during wakefulness and NREM sleep in humans without an upper airway. J Appl Physiol 1996; 81: 274-281.

32. Corfield DR, Roberts CA, Griffiths MJ, Adams L. Sleep-related changes in the human "neuromuscular" ventilatory response to hypoxia. Respir Physiol 1999; 117: 109-120.

33. Morrell MJ, Shea SA, Adams L, Guz A. Effects of inspiratory support upon breathing in humans during wakefulness and sleep. Respir Physiol 1993; 93: 57-70.

34. Tangel DJ, Mezzanotte WS, White DP. The influenze of sleep on the activity of tonic $v s$ inspiratory phasic muscles in normal men. J Appl Physiol 1992; 73: 1058-1068.

35. Tabachnik E, Muller NL, Bryan AC, Levison H. Changes in ventilation and chest wall mechanics during sleep in normal adolescents. J Applied Physiol 1981; 51: 557-564.

36. Millman RP, Knight H, Kline LR, Shore ET, Chung DC, Pack AI. Changes in compartmental ventilation in association with rapid eye movements during REM sleep. J Appl Physiol 1988; 65: 196-202.

37. Schafer T, Schlafke ME. Respiratory changes associated with rapid eye movements in normo- and hypercapnia during sleep. J Appl Physiol 1998; 85: 2213-2219.

38. White JE, Drinnan MJ, Smithson AJ, Griffiths CJ, Gibson GJ. Respiratory muscle activity and oxygenation during sleep in patients with muscle weakness. Eur Respir J 1995; 8: 807-814.

39. Bye PT, Ellis ER, Issa FG, Donnelly PM, Sullivan CE. Respiratory failure and sleep in neuromuscular disease. Thorax 1990; 45: 241-247. 
40. Labanowski M, Schmidt-Nowara W, Guilleminault C. Sleep and neuromuscular disease: frequency of sleep-disordered breathing in a neuromuscular disease clinic population. Neurology 1996; 47: 1173-1180.

41. Bourke SC, Shaw PS, Gibson GJ. Respiratory function $v s$ sleep-disordered breathing as predictors of QOL in ALS. Neurology 2001; 57: 2040-2044.

42. Becker HF, Piper AJ, Flynn WE, et al. Breathing during sleep in patients with nocturnal desaturation. Am J Respir Crit Care Med 1999; 159: 112-118.

43. Manni R, Ottolini A, Cerveri I, et al. Breathing patterns and $\mathrm{HbSaO} 2$ changes during nocturnal sleep in patients with Duchenne muscular dystrophy. J Neurol 1989; 236: 391-394.

44. Phillips MF, Smith PE, Carroll N, Edwards RH, Calverley PM. Nocturnal oxygenation and prognosis in Duchenne muscular dystrophy. Am J Respir Crit Care Med 1999; 160: 198-202.

45. Bourke SC, Shaw PJ, Bullock R, Gibson GJ. Criteria for initiating non-invasive ventilation in motor neurone disease. Am J Res Crit Care Med 2001; 163: A153.

46. Patakas D, Tsara V, Zoglopitis F, Daskalopoulou E, Argyropoulou P, Maniki E. Nocturnal hypoxia in unilateral diaphragmatic paralysis. Respiration 1991; 58: 95-99.

47. Mulvey DA, Aquilina RJ, Elliott MW, Moxham J, Green M. Diaphragmatic dysfunction in neuralgic amyotrophy: an electrophysiologic evaluation of 16 patients presenting with dyspnea. Am Rev Respir Dis 1993; 147: 66-71.

48. Skatrud J, Iber C, McHugh W, Rasmussen H, Nichols D. Determinants of hypoventilation during wakefulness and sleep in diaphragmatic paralysis. Am Rev Respir Dis 1980; 121: 587-593.

49. Camfferman F, Bogaard JM, van der Meche FG, Hilvering C. Idiopathic bilateral diaphragmatic paralysis. Eur J Respir Dis 1985; 67: 65-71.

50. Kimura K, Tachibana N, Kimura J, Shibasaki H. Sleep-disordered breathing at an early stage of amyotrophic lateral sclerosis. J Neurol Sci 1999; 164 : $37-43$.

51. Ververs CC, Van der Meche FG, Verbraak AF, van der Sluys HC, Bogaard JM. Breathing pattern awake and asleep in myotonic dystrophy. Respiration 1996; 63: $1-7$.

52. Serisier DE, Mastaglia FL, Gibson GJ. Respiratory muscle function and ventilatory control. I in patients with motor neurone disease. II in patients with myotonic dystrophy. QMJ 1982; 51: 205-226.

53. Veale D, Cooper BG, Gilmartin JJ, Walls TJ, Griffith CJ, Gibson GJ. Breathing pattern awake and asleep in patients with myotonic dystrophy. Eur Respir J 1995; 8: 815-818.

54. Keesey JC. Does myasthenia gravis affect the brain? J Neurol Sci 1999; 170: 77-89.

55. Ellis ER, Bye PT, Bruderer JW, Sullivan CE.
Treatment of respiratory failure during sleep in patients with neuromuscular disease. Positive-pressure ventilation through a nose mask. Am Rev Respir Dis 1987; 135: 148-152.

56. Hill NS, Redline S, Carskadon MA, Curran FJ, Millman RP. Sleep-disordered breathing in patients with Duchenne muscular dystrophy using negative pressure ventilators. Chest 1992; 102: 1656-1662.

57. Bach JR, Penek J. Obstructive sleep apnea complicating negative-pressure ventilatory support in patients with chronic paralytic/restrictive ventilatory dysfunction. Chest 1991; 99: 1386-1393.

58. Levy RD, Bradley TD, Newman SL, Macklem PT, Martin JG. Negative pressure ventilation. Effects on ventilation during sleep in normal subjects. Chest 1989; 95: 95-99.

59. Barbe F, Quera-Salva MA, de Lattre J, Gajdos P, Agusti AG. Long-term effects of nasal intermittent positive-pressure ventilation on pulmonary function and sleep architecture in patients with neuromuscular diseases. Chest 1996; 110: 1179-1183.

60. Annane D, Quera-Salva MA, Lofaso F, et al. Mechanisms underlying effects of nocturnal ventilation on daytime blood gases in neuromuscular diseases. Eur Respir J 1999; 13: 157-162.

61. Bach JR, Alba AS. Management of chronic alveolar hypoventilation by nasal ventilation. Chest 1990; 97: 52-57.

62. Piper AJ, Sullivan CE. Effects of long-term nocturnal nasal ventilation on spontaneous breathing during sleep in neuromuscular and chest wall disorders. Eur Respir J 1996; 9: 1515-1522.

63. Vianello A, Bevilacqua M, Salvador V, Cardaioli C, Vincenti E. Long-term nasal intermittent positive pressure ventilation in advanced Duchenne's muscular dystrophy. Chest 1994; 105: 445-448.

64. Raphael JC, Chevret S, Chastang C, Bouvet F. Randomised trial of preventive nasal ventilation in Duchenne muscular dystrophy. French Multicentre Cooperative Group on Home Mechanical Ventilation Assistance in Duchenne de Boulogne Muscular Dystrophy. Lancet 1994; 343: 1600-1604.

65. Guilleminault C, Philip P, Robinson A. Sleep and neuromuscular disease: bilevel positive airway pressure by nasal mask as a treatment for sleep disordered breathing in patients with neuromuscular disease. J Neurol Neurosurg Psychiatry 1998; 65: 225-232.

66. Annane D, Chevrolet JC, Chevret S, Raphael JC. Nocturnal mechanical ventilation for chronic hypoventilation in patients with neuromuscular and chest wall disorders (Cochrane review). In: The Cochrane Library, Issue 4, 2001. Oxford, Update Software.

67. Anonymous. Clinical indications for noninvasive positive pressure ventilation in chronic respiratory failure due to restrictive lung disease, COPD, and nocturnal hypoventilation - a consensus conference report. Chest 1999; 116: 521-354. 